\title{
A Special Issue on channelopathies
}

\section{Bernd Nilius}

Published online: 19 March 2010

(C) Springer-Verlag 2010

Keywords Ion channels · Voltage-gated channels . Transient receptor potential $\cdot$ Epilepsy $\cdot$ Diabetes

Ten years after the pioneering and most influential book of Frances Ashcroft about channelopathies [1], Pflügers Archiv publishes what I call a timely up-date of this book, which, of course cannot be reached by a multi-authors Special Issue. The tenth anniversary of another landmark book on channelopathies has to be mentioned [2]. Both books open a wide view on channelopathies. A more focused book on channelopathies in the nervous system reaches also back to 2001 [6]. Meanwhile, many new findings must be added to the mentioned pioneering books. Many new channelopathies appeared, just to think about the advent of TRP channels and their tremendous impact on a plethora of diseases [3-5]. Regrettably, a new edition of these books seems to be unlikely. Therefore, it is very timely to edit a Special Issue which covers at least most of the ion channel families and goes far beyond only the "classical" voltage-operated channels.

A large number of distinct dysfunctions known to be caused by ion channel mutations has been already described and much more are expected to show up. This might be surprising. Imaging that of roughly 20,000 human genes we expect a number of approximately 300 genes for ion channels, the impact on human diseases of those genes responsible for the construction of ion channels might be

B. Nilius $(\bowtie)$

Department of Molecular Cell Biology,

Laboratory Ion Channel Research, KU Leuven,

3000 Leuven, Belgium

e-mail: bernd.nilius@med.kuleuven.be less important. However, ion channels are master regulators of many cell functions reaching from signaling to homeostasis. This makes their role unique and wide-spread! Pointing on the importance of ion channels in the pathophysiology of diseases, all Wikipedia ists may have an immediate look on these special disorders which are caused by disturbed function of ion channels, channel subunits, or regulatory proteins which are connected with a channel protein http://en. wikipedia.org/wiki/Channelopathy. As the encyclopedic knowledge offers, these diseases may be either congenital as mutations in the gene that encodes the channel, they might be acquired or induced by external toxins or environmental disturbances. This Special Issue will almost only focus on the first class, the defective genes. This narrowed view already exceeds the usual space that the publisher of a Special Issue can provide.

The Pflügers Special Issue is written by world leaders in the field of ion channels which all have contributed to this exciting topic of channelopathies. However, living in the time of the World Wide Web, the reader may ask what the importance is of such a review collection if all data might be much easier available on sites for ion channels such as http://www.ensembl.org/index.html, the Mendelian Inheritance in Man database (http://www.ncbi.nlm.nih.gov/ omim) or the very detailed site on channelopathies http:// neuromuscular.wustl.edu/mother/chan.html. This Special Issue, however, gives not only the view but also the personal opinions from ion channel experts. The frame of this Special issue is intentionally wide. It reaches from voltage-dependent to ligand-gated ion channels and we tried to cover most of the channel families, yes, a more encyclopedic view! Probably, nephrologists will look up topical reviews on channel defects involved in kidney diseases. Heart specialists will do the same and neurologists will probably mainly focus 
on channelopathies involved in neurodegeneration, epilepsies etc. This might be the reason that the books like mentioned above are not anymore followed-up by new editions. We have seen a necessity to go back to a more comprehensive view which is less "organ-guided" but starts from the physiology of ion channels. Needless to say, that this is not only a physiological view, but will try to reach also pharmacologists, scientists interested in new drug targets, and, of course, all the specialist clinicians.

As Editor in Chief of Pflügers Archiv, I hope, of course for a high citation of all articles, feeling - if we like it or not - the pressure of impact factors. But of course I hope much more that this special Special Issue may reach a wider public than only the channel community and might offer an extended view on how dysfunctions of ion channels can be involved in our daily life, in health care and therapeutics and may intellectually add a lot to our in-depth understanding of human diseases.
I wholeheartedly thank all who have contributed to this Special issue!

\section{References}

1. Ashcroft FM (2000) Ion channels and disease: channelopathies. Academic, Boston

2. Lehmann-Horn F, Jurkat-Rott K (2000) Channelopathiescommon mechanisms in aura, arrhythmia and alkalosis. Elsevier, Amsterdam

3. Nilius B (2007) TRP channels in disease. Biochim Biophys Acta 1772:805-812

4. Nilius B, Owsianik G (2010) Channelopathies converge on TRPV4. Nat Genet 42:98-100

5. Nilius B, Owsianik G, Voets T, Peters JA (2007) Transient receptor potential cation channels in disease. Physiol Rev 87:165-217

6. Rose MR, Griggs RC (2001) Channelopathies of the nervous system. Butterworth Heinemann, Oxford 